\title{
Lean and Six Sigma
}

\author{
Ishfaq Shafi Masoodi ${ }^{1}$, Chitranjan Kumar ${ }^{2}$ \\ ${ }^{1}$ Research Scholar, AL FALAH University, Haryana, India \\ ${ }^{2}$ Assistant Professor, AL FALAH University, Haryana, India
}

\begin{abstract}
The purpose of this thesis is to investigate the trends in published research concerning Lean Six Sigma and continuous improvement. We use published research in the areas of continuous improvement, for example Lean Manufacturing, Six Sigma, Lean Six Sigma, and Sustainability to show that this growth in popularity is spurring more research, technical papers, and a general direction within academia and the business community. The six sigma literature and lean six sigma literatures have continued to grow. Specifically, the volume of articles on lean six sigma has grown $415 \%$ by one measure in five years. Yet, in proportion the majority of relevant articles continue to be on six sigma alone. Relevant literatures focusing on overlaps of six sigma with other concep ts such as simulation, optimization, and sustainability also have experienced rapid growth. We found a change in the perceptions about success factors from a previous emphasis on top management commitment to a new emphasis on structured approaches. This de velopment combined with the rise of new technology intensive methods such as optimization and simulation which are combined with lean sigma indicate to us a maturing of the literature and the organizations that support it. Finally, by examining statistics about the document database, we develop hypotheses about the future including those relating to sustainability and energy conservation and lean six sigma methods.
\end{abstract}

Keywords: Lean, Six Sigma

\section{Introduction}

Lean Manufacturing and Six Sigma have been continuous improvement tools that manufacturers have been using for over 20 years. The lean manufacturing ideology emphasizes that the main "thrust" is having all of the tools working together to create a streamlined, high quality system that produces products at the demand of the customer with little or no waste (Shah and Ward, 2007). Whereas Six Sigma's foundation is in statistical analysis and within Six Sigma, the common measurement index is defects per million opportunities which could include anything from a component, piece of material, or an administrative form (Brady and Allen, 2005). Six Sigma uses the very formal DMAIC process, which breaks down a specific project into phases. Both sets of tools have allowed companies to reduce costs and improve quality throughout their manufacturing operations. In some organizations Lean Manufacturing and Six Sigma have morphed into a new subset of tools under the title of Lean Six Sigma.

In this paper, we will show the trends in published papers from Lean Manufacturing, Six Sigma, and Lean Six Sigma over the past twenty years. We are looking to see if these continuous improvement methodologies have grown in popularity or have faded over time. Our initial hypotheses was that research and publications in the fields of Lean Manufacturing, Six Sigma, and Lean Six Sigma has increased over the past twenty years however would be on the decline in more recent years. We will depict and analyze the trends in all three subject areas within the paper.

Next, we examine more closely the research that was published specifically under the category of Lean Six Sigma. We will break down the research articles in multiple categories to show who and what is being published. Specifically, we will show Authorship, Specific Industries, Research Topics or Methods, and Success Factors. The categories used to break down the Success
Factors was used initially to correspond to the quality management practice used by Sousa and Voss and successfully used to analyze Six Sigma literature by Brady and Allen in 2005.

The literature search analysis that we did initially around continuous improvement and the more detailed analysis, specifically, around Lean Six Sigma, allowed us to predict where future research in the area of continuous improvement would evolve. We looked into the area of "green" or sustainability since it appeared to us this is a trendy subjectand we also looked at simulation and optimization because these seemed to us to be a natural evolution in continuous improvement. We then discuss the Capability Maturity Model and how it could be applied to continuous improvement.

\subsection{Lean Manufacturing}

Lean thinking originated within the Japanese automobile industry following World War II and is principally based on the Toyota Production System (TPS). Lean is much more than a combination of tools, methods and principles. It is the mindset of everyone who works within the organization (Drew et.al. 2004). Lean is an integrated system of principles, practices, tools, and techniques that are focused on reducing waste, synchronizing work flows, and managing production flows (Koninget.al. 2006).

Lean is concentrated with the reduction of waste ("muda" in Japanese). The understanding that if you reduce waste within the Value Stream and ultimately within the organization, then a company's throughput will increase. Many companies most commonly measure throughput in units per man hour. Through the principles of lean, such as Value Stream mapping, Single Minute Exchange of Dies [SMED], line balancing, etc. allows an organization to increase the number of units and also reduce the number of man hours needed to make the necessary production. From the origination of Lean thinking at Toyota Corporation, these principles have moved to other 


\section{International Journal of Science and Research (IJSR) \\ ISSN (Online): 2319-7064}

Index Coperni cus Value (2015): 78.96 | Impact Factor (2015): 6.391

Japanese automotive manufactures and then to the American automotive companies. The continued success of these companies that have implemented lean has propelled this methodology across manufacturers of all sectors, not just automotive. By eliminating waste, companies have increased throughput with fewer resources thus a higher bottom line. Due to this continued success over an extended amount of time, many academics and industry professionals have studied and researched lean techniques, methodologies and overall mindset.

\subsection{Six Sigma}

There are multiple definitions of what Six Sigma is and how it is explained. It has been written in multiple papers the need to standardize the actual definition. In Brady and Allen's paper (Brady and Allen, 2005), they go through some of the variations to the definition starting with Linder man's definition and go through the various other authors that give their opinions on how it should be defined. Ultimately, Six Sigma's foundation is in statistical analysis and within Six Sigma, the common measurement index is defects per million opportunities and can include anything from a component, piece of material, and an administrative form (Brady and Allen, 2005). This foundation started at Motorola in 1979 and they were able to change the mindset that improving quality costs money.

They proved that improving quality actually reduced operating costs and increased customer satisfaction (Harry and Schroeder, 2000). One of the main methodologies within Six Sigma is the DMAIC process, which breaks down a specific project into phases. These phases, known as the DMAIC methodology, are defined as Define, Measure, Analyze, Design, and Control. This methodology guides the project team from the beginning of the project [Define] to maintaining the results [Control]. A main concept that needs to be understood is that Six Sigma is a performance target that applies to a single characteristic. This single characteristic in Six Sigma methodology is known as a critical-to-quality characteristic [CTQ] (Harry and Schoeder, 2000). This single critical-to-quality characteristic not the total product is the goal of Six Sigma. Six Sigma has been proven to improve both process and product quality. Due to the success that companies such as Motorola, GE, etc. have demonstrated in their manufacturing operations, Six Sigma methodology has moved to other areas such as Healthcare, Service Industries, etc. This outreach to other industries has continued to make Six Sigma a popular subject in both industry and academia. Due to this popularity, we hypothesize that the number of published articles has increased recently over time.

\subsection{Lean Six Sigma}

Lean Six Sigma is becoming the leading continuous improvement technique used by companies in various industries. From manufacturing to healthcare to IT, Lean Six Sigma maximizes efficiency and helps control each step of the process. Lean Six Sigma is an approach that is focused on improving quality, increasing productivity and reducing cost in any organization. (George, 2005) This is a logical definition since Lean Six Sigma is the combination of two different, but complimentary, approaches to continuous improvement Lean and Six Sigma. Previously organizations chose to use either Lean or Six Sigma where now they have decided to use the blended techniques found in Lean Six Sigma. What companies have found out is that their results are much greater using the Lean Six Sigma methodology instead of Lean or Six Sigma individually. The reason behind this conclusion is that both Lean and Six Sigma have their benefits but also their flaws whereas Lean Six Sigma just incorporates the best techniques, principles and methodologies for continuous improvement. As the IBM consulting team, led by Hans Skalle, writes that Lean Six Sigma has also incorporated components of the systems based approach to process improvement found in Goldratt's Theory of Constraints. (Skalle, 2008). This statement confirms that continuous improvement methodology, led by Lean Six Sigma, continues to change and adapt to the challenges faced in the business environment.

In this paper, we will examine published Lean Six Sigma articles in multiple ways. We will examine the time series analysis of the number of articles published over time and will do a "deep dive" into specific articles published over the past six years.

\section{Literature Review}

\subsection{General}

Within this paper we did various literature reviews to see the data from items that were being published. We chose to do Literature reviews because they are good sources of data for trends in both academia and in industry. Literature searches show where people are concentrating their research and will give an indication of future research trends. In our initial literature search, the intent was to see the trends over a specified time series. In this case, we went back over the past twenty year period, 1990 through 2010, in order to capture the recent trends in the data and specifically wanted to see when within the time series did significant changes occur. First, we started with articles that referenced "Lean Manufacturing" within the article and then we moved on to "Six Sigma" and finally "Lean Six Sigma". We used both Google Scholar and the Science Citation Index databases as our primary search databases. We used these databases because they are commonly used are wide ranging databases.

Our initial literature search was using Google Scholar with the term "Lean Manufacturing" used anywhere within the article. We also broke down the data to look at Engineering and Business areas within Google Scholar. The Engineering areas included journals from the Engineering, Computer Science and Mathematics fields and the Business areas included journals from the areas of Business, Administration, Finance, and Economics. 


\section{International Journal of Science and Research (IJSR) \\ ISSN (Online): 2319-7064}

Index Coperni cus Value (2015): 78.96 | Impact Factor (2015): 6.391

As you can see from the figure, there have been a significant number of articles published in both business and engineering journals with this subject. What is even more interesting is the number of published articles has increased significantly overtime particularly in the past 5 years $(2006-2010)$.

We did an additional literature search on this topic using the Science Citation Index databases. We wanted to confirm that the trends were similar in this database. We used the search term "Lean Manufacturing" from the dates $1990-2010$. We also restricted the findings where the search terms only appeared in the "Topic". A screen shot of the search screen is shown below.

The Science Citation Index primarily shows articles that appear in technical journals. As the graph depicts, there is still a steady increase in the number of articles, however, nowhere near the \% increase or magnitude of articles we found with the Google Scholar search.

\subsection{Literature Review}

In this section, we present a characterization of the articles in the database by using the descriptors that we defined. The purpose is to show specific trends and also overall identification, such as country of origin. We felt that is necessary to breakdown the characteristics of the articles in the database to make sure we did not miss any conclusions that the articles presented. Next, we looked at the articles to see if there were any connections with Sustainability, Simulation, or Optimization. Finally, we discuss the success factors that were presented within the data and present them in tables so that we understand which success factors were most often cited with the literature.

\subsection{Literature Trend}

The first breakdown of the database articles is what we described as authorship. Authorship is defined as the author(s) from Academia, Industry, or both. Most articles were written by someone or the team of authors that came from academia

\subsection{Research Topics and Methods}

We then turned to the various research topics and methods that were used in the Articles that made up the database. We consolidated the categories to Theoretical with Application, Case Study, Comparative, Literature Review, Survey, and Other. This information will allow us to make some conclusions about the research articles in our database that can be used to support our hypotheses or predict future research.

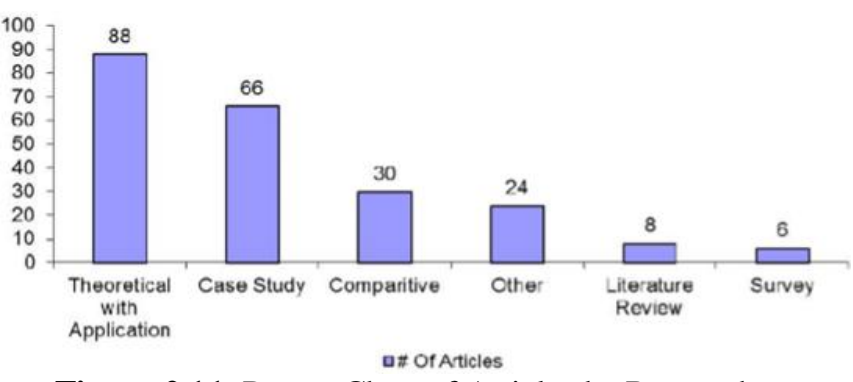

Figure 2.11: Pareto Chart of Articles by Research Approach

\subsection{Success Factors}

In our literature database, $26 \%$ of the articles made specific reference to at least one "success factor" that was necessary for success. We identified 13 distinct success factors mentioned by Brady and Allen and originally by Sousa and Voss to describe the dimensions of quality management practices. The graph below shows the percentage of articles that specifically mention on these specific success factors.

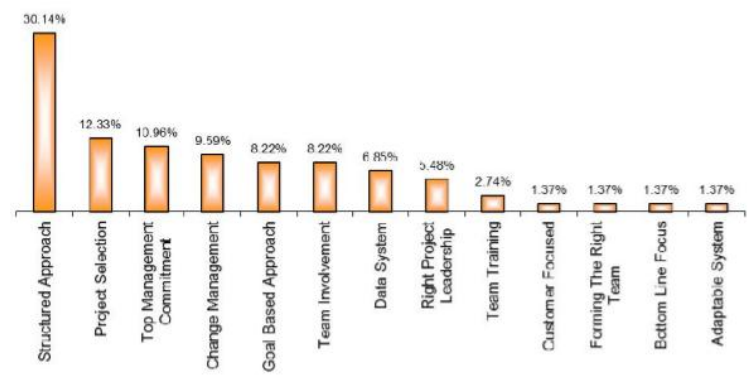

Figure 2.12: Percentage of Articles That Has Specific Success Factor

As you can see from the graph, Structured Approach is the success factor that is most referenced within the articles in the database. This is followed by Project Selection and Top Management Commitment. These results follow what has been written about Lean, Six Sigma, and Lean Six Sigma that one needs to be disciplined and hold true to a structured approach from problem identification to data analysis to corrective actions. Compared with results from Brady and Allen (2006), the results suggest a change in the perception about project success factors. Previously, the emphasis was on top management commitment $(27 \%$ and now $11 \%$ ) and now there is a greater emphasis on the application of a structured approach (30\% and formerly $8 \%$ ). Intuitively, this might be explained by greater acceptance among top management of six sigma related methods.

\subsection{Synthesis and Future Research}

In this section, we attempt to synthesize the results of our literature search and project possible directions that future research might take. We also explore additional data related to sustainability which our own personal experience suggests is related to lean six sigma in part because the framework of lean six sigma is currently structuring sustainability improvement and energy conservation efforts in many industries. Evolution of Lean to Six Sigma to Green / Sustainability - Future Research 


\section{International Journal of Science and Research (IJSR) \\ ISSN (Online): 2319-7064}

Index Coperni cus Value (2015): 78.96 | Impact Factor (2015): 6.391

The theory behind the evolution from lean to Six Sigma to Lean Six Sigma to sustainability here is that companies start with Lean tools to reduce cost and increase throughput. These tools focus around head count optimization, downtime reduction and ultimately an increase in throughput, which is usually measured in units per plant hour. Then companies expand their tools to include Six Sigma which focuses around quality / first pass yield indicators. As the opportunities become harder to come by, companies look at green / energy reduction as a source of continuous improvement. The difficulty with trying to do a literature search around sustainability or "green" is that there are so many descriptors for that topic and a term such as sustainability may be used to describe something that is not "green" and will pick up data that is not relevant. Therefore, we show many graphical representatives that feel encompass "green" or sustainability and its correlation to lean. In this first graph, the following charts show some of the literature trends. Our first look into this evolution was "Toyota Production System", "Energy Reduction" and "Lean." As stated earlier, we used Toyota Production System (TPS) as a search term because it is synonymous with lean methodology and we also used lean also just so we picked up all relative articles. For our sustainability / "green" term, we use energy reduction since it is very relevant to waste reduction, which is the mantra on Lean / TPS. We used Google Scholar for our literature search in order to stay consistent with our earlier searches.

\section{Lean Six Sigma, Simulation, and Optimization - Future Research}

Another forecast that we can derive from this research is that continuous improvement seem likely to evolve from Lean Six Sigma in many organizations. These High cost Producer View point Low cost Society View point Customer View point Low value High value Low value High value Six sigma Lean Six sigma Lean "Green Lean Six Sigma” organizations will move from Lean Six Sigma to Simulation and then finally to Optimization. This will happen because it becomes ever so difficult to find the "low hanging fruit" and companies still continue to strive to reduce costs within their operations. Usually what you see is that Lean Manufacturing principles are the best tools that allow an organization to reduce manpower and increase their units per man-hour. Lean Manufacturing principles are the easiest to adopt since it the least difficult for people to understand and thus adapt within their organization. Once this is not their number one opportunity, companies need to look at first pass yield projects. The tools that are best suited to do this are Six Sigma tools and thus the continuous improvement tools must evolve. An organization never stops using the core tools that they have developed / used but it is necessary to add additional tools to their initiatives to cut costs. Within the literature that I examined, you can see the number of articles that contained the terms Lean Six Sigma, Simulation and Optimization has increased over the past 6 years. Specifically, we did a Google Scholar search with the Search Terms: "Lean Six Sigma", "Simulation", and "Optimization" from 2005 - 2010 where the search terms would Appear Anywhere in the Article. The articles either appeared in "Business journals or "Engineering" journals.

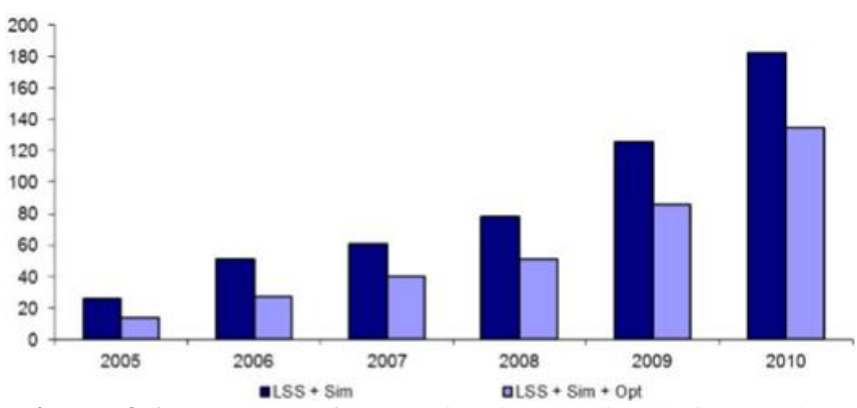

Figure 3.1: Increase of Lean Six Sigma, Simulation, and Optimization Articles overTime

\subsection{Lean Six Sigma, Simulation, and Optimization - Future Research}

Another forecast that we can derive from this research is that continuous improvement seem likely to evolve from Lean Six Sigma in many organizations. These High cost Producer View point Low cost Society View point Customer View point Low value High value Low value High value Six sigma Lean Six sigma Lean "Green Lean Six Sigma” organizations will move from Lean Six Sigma to Simulation and then finally to Optimization. This will happen because it becomes ever so difficult to find the "low hanging fruit" and companies still continue to strive to reduce costs within their operations. Usually what you see is that Lean Manufacturing principles are the best tools that allow an organization to reduce manpower and increase their units per man-hour. Lean Manufacturing principles are the easiest to adopt since it the least difficult for people to understand and thus adapt within their organization. Once this is not their number one opportunity, companies need to look at first pass yield projects. The tools that are best suited to do this are Six Sigma tools and thus the continuous improvement tools must evolve. An organization never stops using the core tools that they have developed / used but it is necessary to add additional tools to their initiatives to cut costs. Within the literature that I examined, you can see the number of articles that contained the terms Lean Six Sigma, Simulation and Optimization has increased over the past 6 years. Specifically, we did a Google Scholar search with the Search Terms: "Lean Six Sigma", "Simulation", and "Optimization" from 2005 - 2010 where the search terms would Appear Anywhere in the Article. The articles either appeared in "Business journals or "Engineering" journals.

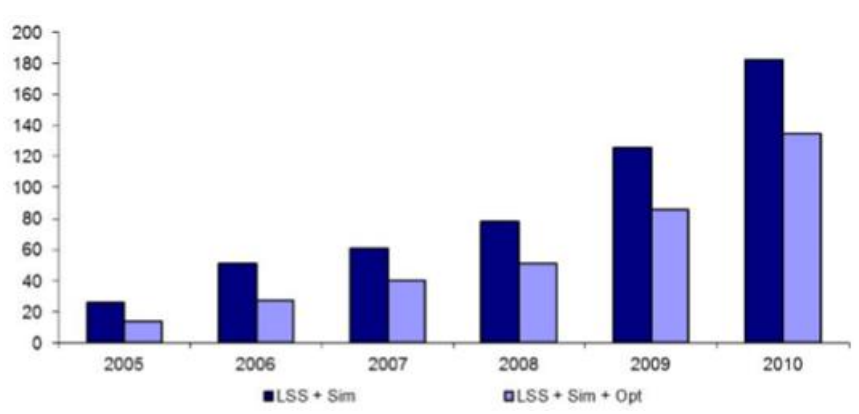

Figure 3.2: Increase of Lean Six Sigma, Simulation, and Optimization Articles over Time 


\section{International Journal of Science and Research (IJSR) \\ ISSN (Online): 2319-7064}

Index Coperni cus Value (2015): 78.96 | Impact Factor (2015): 6.391

As you can see from the graph, there is an upward trend in the number of articles published with the terms Lean Six Sigma, Simulation and Optimization. With the limited number of articles that were published from 2005 to 2010, it is not conclusive that there is any true relationship between these identifiers; however, the theory needs to be reviewed in the future.

We then took the opportunity to put together this theory with Lean Six Sigma, Simulation, and Optimization and try to adapt it to the Capability Maturity Model. The Capability Maturity Model (CMM was created by the Carnegie Mellon University (CMU) and refers to a development model elicited from actual data. The data was collected from organizations that contracted with the U.S. Department of Defense, who funded the research, and became the foundation from which CMU created the Software Engineering Institute (SEI). Like any model, it is an abstraction of an existing. As you can see from the graph, there is an upward trend in the number of articles published with the terms Lean Six Sigma, Simulation and Optimization. With the limited number of articles that were published from 2005 to 2010 , it is not conclusive that there is any true relationship between these identifiers; however, the theory needs to be reviewed in the future.

We then took the opportunity to put together this theory with Lean Six Sigma, Simulation, and Optimization and try to adapt it to the Capability Maturity Model. The Capability Maturity Model (CMM was created by the Carnegie Mellon University (CMU) and refers to a development model elicited from actual data. The data was collected from organizations that contracted with the U.S. Department of Defense, who funded the research, and became the foundation from which CMU created the Software Engineering Institute (SEI). Like any model, it is an abstraction of an existing

\section{Conclusions}

We have categorized the literature relating to six sigma, lean six sigma, and related topics. We have seen evidence that there has been a measured increase in the overlap of literature on lean and six sigma but that the six sigma topic continues to be far more popular than lean six sigma or lean.

We have also seen an increase in exploration of topics associated with relatively mature organizations including those relating to optimization and simulation. The observed evolution in the perceived project success factors which formerly focused on management commitment and now focus on structured approaches probably reflects growing organizational acceptance and maturity levels. Further, we introduced a diagram which intuitively maps out concepts attempting to put the green or sustainability into the context of six sigma related literatures. We believe continuous improvement will continue to evolve and become more important in all sectors of business not just manufacturing. With the advent of sustainability and its importance to the customer, this could lead to the next frontier of continuous improvement or we can see the movement to a more technical transformation from simulation then to optimization.

\section{References}

[1] Ayadi Youssouf, Chaib Rachid, and Verzea Ion (2014), "Contribution to maintain the optimization of strategy of maintenance by Lean Six Sigma", ELSEVIER, Eight International Conference on Material Sciences (CSM8-ISM5), Vol. 55, pp. 512518.

[2] Gaurav Tiwari and S. Kesavan (2016), 'Lean, Green and DMADV tool based approach for an effective execution of residential building construction", International Journal of Engineering and General Science, Vol. 5, Issue no. 5, pp. 383- 385.

[3] Jonny and Jessika Christyanti (2012), 'Improving the quality of asbestos roofing at PT BBI using six sigma methodology", ELSEVIER, International Congress on Interdisciplinary Business \& social Science, Vol. 65, pp. 306-312.

[4] Kuo-Liang lee and Yang Su (2013), "Applying six sigma to quality improvement in construction", Journal of Management in Engineering, ASCE, Vol. 29, pp 464-470

[5] Low Sui Pheng, \& Mok Sze Hui (2004), "Implementing and applying six sigma in construction", Journal of Construction Engineering and Management, ASCE, Vol.130, pp. 482-489.

[6] Mehmet Tolga Taner (2013), "critical success factors for six sigma implementation in large-scale Turkish construction companies", International Journal of Management and Marketing, Vol. 3, Issue no. 4, pp. 212- 225.

[7] Rodney a. Stewart and Clinton a. spencer (2006), "Six sigma as a strategy for process improvement on construction projects: A case study", Construction of Management and Economics, Vol. 24, Issue no. 4pp. 339-348.

[8] Sneha P Sawant, Smita V. Pataskar (2014), "Applying six sigma principals in the construction industry for quality improvement", International Conference on Advance Engineering and Technology -ICAET, ISBN: 978-1-63248-028-6.

[9] Sunil Srivastava, K. K. Pathak (2016), "preparation of questionnaire for training needs analysis of construction project", SSRG International Journal of Civil Engineering, Vol. 3, issue no. 1, pp. 106-109

[10]Sunil V. Desale, Sharad V. Deodhar (2013), "Identification and eliminating waste in construction by using lean and six sigma principles", International Journal of Innovative Research in Science, Engineering and Technology, National Conference on Recent Advances in Civil Engineering (NCRACE), Vol. 3 , Issue no. 4. 